\title{
Dynamics of Speed Control of Dc Motor using Combine Armature and Field Control with Pi Controller
}

\author{
Oti Stephen Ejiofor, Agada Stephen C., Obe Chinedu, Salihu Ahmed, Ogbuefi Uche C.
}

\begin{abstract}
This work examines the intrigues associated with the speed control of DC motor by nonlinear joint control of the voltage of the armature cum the field current in conjunction with the proportional integral controller. In the case of controlling the armature, the field current component is kept constant while the armature in contained with variable voltage. However, in the case of controlling the field, the voltage of the armature is kept constant while the field contends with a variable voltage. Both the field and the control of armature were used to acquire a DC motor speed control enhancement which offers a stability of the system. The proportional integral (PI) is for the purpose of extension for identification of better alternative. As consideration is given to the electrical, electromagnetic and the motional or mechanical arrangements, a model is developed for the separately excited DC motor (SEDM) which is mathematically analyzed. The originating models of the DC motor speed control schemes are simulated with the help of MATLAB/Simulink. The results obtained herein would be very useful for the control and process engineering oufits.
\end{abstract}

Keywords: Armature control, DC motor, Field control, PI controller, Speed control,

\section{INTRODUCTION}

The DC motor consists mainly of windings mounted on the rotor referred to as armature and the static windings referred to as the field poles. Virtually in all DC motors, except permanent magnet brushless motors, current movement is via the carbon brushes towards the armature .This is enabled by the sliding action of set of copper surfaces on the rotor end in a commutation process. The armature coils hold the soldered commutator bars. Depending on the rotor position, the brush with commutator arrangement gives rise to sliding switch which makes some certain armature parts to be energized.

Revised Manuscript Received on February 27, 2020.

* Correspondence Author

Oti Stephen Ejiofor, Electrical Engineering Dept, University of Nigeria, Nsukka Enugu State Nigeria. Email:stephen.oti@unn.edu.ng

Agada Stephen C, Electrical/Electronic Engineering Dept, Michael Okpara University of Agriculture, Umudike Abia State, Nigeria. Email:joychag1@gmail.com

Obe Chinedu Titus, Electrical Engineering Dept, University of Nigeria, Nsukka Enugu State Nigeria. Email:chinedu.obe@unn.edu.ng

Ahmed Salihu, Electrical Engineering Dept, University of Nigeria, Nsukka Enugu State Nigeria. Email:rufai.salihu@unn.edu.ng

Ogbuefi Uche C*, Electrical Engineering Dept, University of Nigeria, Nsukka Enugu State Nigeria. Email:uche.ogbuefi.oti@unn.edu.ng

(C) The Authors. Published by Blue Eyes Intelligence Engineering and Sciences Publication (BEIESP). This is an open access article under the CC BY-NC-ND license (http://creativecommons.org/licenses/by-nc-nd/4.0/)
The resulting development introduces north magnetic pole and south magnetic pole on the rotor. These however initiate attraction to or repulsion the by north and south poles on the stator, that originated from the passage of direct current through windings of the field. From this, the rotor starts to rotate, action which emanates from the magnetic attraction and repulsion. A very good advantage of DC motors has to be in the control of the speed. Noting that the speed and the armature voltage are in direct relationship although varies inversely proportional with the produced magnetic flux by the poles, attempts to regulate the armature voltage and/or the field current would for sure alter the value of the speed of rotor. This day, variable frequency drives has the capability of providing accurate speed control for alternating current motors, however, this is done at the expense of power quality, because the solid-state switching chips of the drives are highly associated with harmonic spectrum. The DC motor according to [1] rules out such effects on the quality of power. DC motors are of great importance and so, it is being employed in many applications including and not limited to electric trains, cranes, robotics manipulators and in vehicular forms. They need speed regulation to accomplish their tasks. Primarily DC motor speed control has been achieved by voltage regulation. Semiconductors in like manners have been used as switching devices to regulate speed as in these examples- MOSFET, IGBT and GTO. It has taken long that DC motors are used as adjustable speed machines with different degrees of operational options manifesting. Due process applications require that, the motor is to be accurately controlled to give the anticipated performance. Different types of control or regulating approaches like proportional $(\mathrm{P})$, proportional integral (PI), proportional integral derivative (PID), adaptive and fuzzy logic controller (FLC) are already in use for the control of speed of DC motors [2]. In this work, PI control will be employed; To remove the steady state error due to $\mathrm{P}$ controller, the PI controller is usually applied. In this manner, integral increases the response of the system to a given error over time until it is corrected. Mostly PI controllers are used in industries because; the noise producing derivative action is neglected [3]. As long as variable speed drive of wide range operation is specified, DC motor will always be the most common select. Of the three DC motors types: series, shunt and separately excited DC motors, the latter are most often used. When the armature voltage and the field voltage are varied, different speeds result. An outstanding characteristic of separately excited DC motor arrangement is its capability to, at low operation speed yield high starting torque. 
The conventional cascade PID technique is commonly used in DC motor speed cum position control; it doesn't suite cases of high performance, owing to low strength of PID controller. Several researches are ongoing on different new control strategies in order to improve the performance of the system. This work majorly aims at a way to estimate and control the speed of DC motor with the use of combine armature and field control using MATLAB application. Its specific objectives are to examine the DC motor speed control using combine armature and field control and to decide the performance following the result of the simulation. The main purpose of speed control is for the fact that there are several case abound like in robotics where there is the quest to vary the speed of motor because it cannot perform effectively unless there is a precise way in which the speed is regulated. We can, in DC motor adjust the speed well below and above the rated speed. This can be done either field current control method or by armature voltage control method. The studies on DC motor speed control using combine armature and field control helps towards high performance motor drives at reduced operation speed is of immense importance in the industries. The controller will have the effect of increasing the stability of the system and reducing the overshoot and improve the speed response. As the age of motor increases, its performance also decreases with aging, so it is of important to evaluate the performance of motor from time to time for efficient operation as imagined in the armature current cum field flux interface in the rotor to produce torque [4]. The scopes of this work included and not limited to the investigation of armature and field currents that are used in estimating and controlling techniques in the simulation. DC motor speed control can be controlled below and above the rated speed by using field current and armature voltage control techniques. By the use of field control, the case of speed control above the rated speed is achieved while as you vary the armature voltage the case of below the rated speed applies. It also looked at the mathematical modeling and computer simulation [5] so as to unveil the performance capabilities of the motor. Here, PI controller is designed to supervise and control the speed response of the DC motor while Matlab is used for simulation.

\section{LITERATURE SURVEY}

The importance of DC motors and its use in many applications and industrial fields cannot be over emphasized. Its simplicity; simplicity of use, reliability and favorable cost is considered a mainstay of their use in the industry. Due to these features, DC motors are used widely in variable speed drives and in applications requiring position control. Its characterizing feature of high torque provision as load sustainable property is a property that is very much reckoned with DC motor. The speed is directly proportional to the armature voltage and inversely proportional to the field current. According to [6], in armature control, it is feasible to obtain steady base speed up to the rated throughout the range of the load. Although, taking field control for instance, the full percentage steady base speed up to additional 20\% - 30\% rated is feasible, it has attendant loss of the torque developed by the motor. This has therefore prompted many researchers to be focused most on combining the armature and field control to get the benefit of both. The DC motor principle and the processes of speed regulation using armature control approach, methods of field control and that of instant stopping of the DC series motor in times of emergency were described in [1,7]. The field current is held constant in the case of armature control scheme and variable voltage is applied to the armature. The armature voltage is held constant in the case of field control mode, and a variable voltage is applied to the field. A requirement of the speed variation of series motor using armature control method is that the armature terminals should have voltage applied to it, changed; this is done with the field current remaining constant. In the scheme requiring control of the field, field is weakened and strengthened as is required. One of the main ideas behind this paper is to make easy the derived understanding, on how the desired controls can be effectively achieved. According to [4,7], efficiency value associated with combined armature voltage and field current control of Separately excited DC motor is $1.02 \%$ more than that of armature control of separately excited DC motor at full load torque condition. Continuing that at half load state the efficiency of combined armature and field control of DC motor is increased by $1.89 \%$ greater than the armature voltage control of DC motor. The change in load torque condition does not affect the speed of separately excited DC motor since is controlled. In [6-8], Fuzzy logic controller was used as an intelligent control method to decide how much the DC motor depends on the armature circuit or on the field circuit to yield the requisite speed. The FLC decision should be valid for the whole range of the load torque in a way that increases the motor efficiency. Vijay Singh et al [9] tested and evaluated how the DC motor with conventional controller like PID controller performed and the results have been likened to that of fuzzy based PID controller. On comparism to conventional controller they found that Fuzzy based PID controller gives enhanced speed feedback, however, conventional controller gives enhanced speed response when load is changed at the expense of long settling time. The above cases were verified in Matlab/Simulink environment. A lot of other literatures [10-17] have shared one or more common features with this work. Herein, the combined field and armature control systems have been considered and worked upon using Matlab/Simulink. Open and closed loop systems were compared to show the effect of PI controller on the stability of a system.

\section{METHODOLOGY}

\subsection{CONTROLLER DESIGN}

The amplitude of voltage to be applied is what controls the speed of the motor. The pulse width modulation scheme is used to regulate the applied voltage magnitude with the desired speed being regulated by a speed controller that has been realized as a conventional PI controller.

Published By: 
What goes in to the PI controller is obtained by considering differential variance between the real or actual speed as compared to the desired speeds. It is with the same result of different that the desired DC bus current can be obtained. The desired DC bus current is regulated using a current controller that is realized as a conventional PI controller. The result of actual minus DC bus current has to be the input that will be fed to the PI controller which invariably makes use of the difference to control the duty cycle of the pulse width modulation pulses that eventually tallies with the voltage amplitude needed to sustain the needed speed. In this task, a PI speed controller is considered. The PI controller is standard and has over the time demonstrated to be a way out for use and application in the industry. An absolute gain derivable remains its comparatively modest structure, that enables for easy understanding and implementation, and which allows the other classy control schemes, like model predictive control, to have it as a base. A highly variable system needed different PI gains when compared to a system which wallows in a constant speed. Moreover, technologydriven tools which dwell over wide range of speeds, need different gains at the smaller and higher ends of the speed range so as to avoid overshoots and oscillations. In General terms, regulating the proportional and integral constants for a large speed control course is dear and does not save time. The duty is made hectic and unbearable if one encounters where false PI constants are occasionally allowed in as a result of system ignorance. The values of proportional constant $\left(K_{p}\right)$ and Integral constant $\left(K_{\mathrm{i}}\right)$ are gotten by calculations and they are 1.19 and 1.812 respectively for this case.

\subsection{MATHEMATICAL MODEL OF THE} SEPARATELY EXCITED DC MOTOR

When a Separately Excited DC motor is exhilarated by a field current of $I_{f}$ and armature current of $I_{a}$ flows in a circuit, the motor develops a back EMF and a torque to balance the load torque at a particular speed. The $I_{f}$ is independent of $I_{a}$. Each winding has a separate supply. Produced torque is the result of the interaction of field flux and armature current at rotor side.

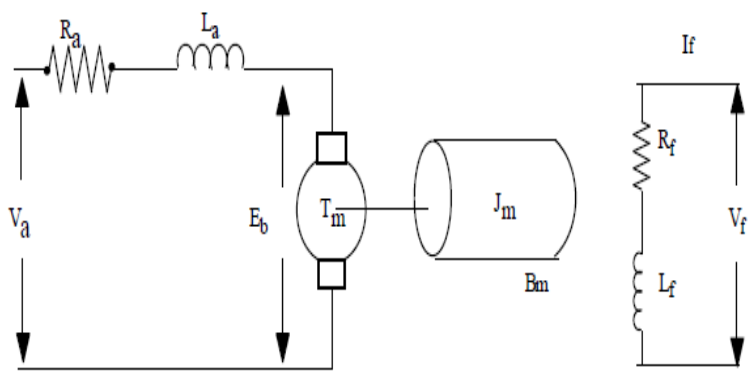

Fig. 1: Separately Excited DC Motor model

From the armature windings, we have the following equation using KVL.

Where; $e=k_{b} i_{f} \omega_{m}$ back emf

(1)

From the field winding, we have that;

$v_{f}=R_{f} i_{f}+L_{f} \frac{d i_{f}}{d t}$

The mechanical equation of the motor is given as

$T_{m}=T_{L}+B_{m} w_{m}+J \frac{d w_{m}}{d t}$

$T_{\mathrm{m}}=k_{b}, i_{f}, i_{a}$
Hence, to create the model, we make $\frac{d i_{m}}{d t}, \frac{d i_{f}}{d t}$ and $\frac{d w_{m}}{d t}$

subject in equation (1) through (3) i.e

$\frac{d i_{a}}{d t}=\frac{-R_{a}}{L_{a}} i_{a}-\frac{k_{b}}{L_{a}} w_{m} i_{f}+\frac{v_{a}}{L_{a}}$

$\frac{d i_{f}}{d t}=-\frac{R_{f}}{L_{f}} i_{f}+\frac{v_{f}}{L_{f}}$

$\frac{d \mathrm{w}_{m}}{d t}=\frac{1}{J_{m}}\left[T_{m}-B_{m} w_{m}-T_{L}\right]$

$T_{m}=k_{b}, i_{a}, i_{f}$

Where; $l_{m}=$ moment of inertia, $w_{m}=$ speed of motor in radian/seconds; $B_{m}=$ viscous coefficient, $v_{f}=$ field voltage, $T_{L}=$ Load torque, $i_{f}=$ field current, $T_{m}=$ motor or electrical torque, $v_{a}=$ Armature current, $E_{b}=$ back emf of the motor $k_{b}=$ motor constant, $v_{a}=$ Armature voltage.

\subsection{TRANSFER FUNCTION OF ARMATURE-CONTROLLED SEPERATELY EXCITED DC MOTOR}

From KVL,

$V_{a}(t)=i_{a} R_{a}+L_{a} \frac{d i_{a}}{d t}(t)+E_{b}(t$

$T_{m}=T_{l}+I_{m} \frac{d m_{m}}{d t}(t) B_{m} w_{m}(t)$

$E_{b}(t)=k_{m} \cdot w_{m}(t)$

$k_{m}=k_{b} \cdot i_{f}$.

$T_{m}(t)=k_{m \times} i_{\alpha}(t)$

Taking Laplace transform of equation (9)

$v_{\alpha}(s)=R_{a} \cdot I_{a}(s)+s L_{a} \cdot I_{a}(s)+E_{b}(s)$

$v_{a}(s)=I_{a}(s)\left[R_{a}+s L_{a}\right]+E_{b}(s)$

$I_{a}(s)=v_{a}(s)-E_{b}(s)\left[\frac{1}{R_{a}+s L_{a}}\right]$

From equation (10),

$T_{m}(s)=T_{L}(s)+J_{m} w_{m}(s)+B_{m} w_{m}(s)$

$\mathrm{w}_{\mathrm{m}}(s)=\frac{T_{m}(s)-T_{\mathrm{L}}(s)}{\left(s h_{m}+B_{\mathrm{m}}\right)}$

From equation (12),

$T_{m}(s)=k_{m} \cdot I_{a}(s)$

From equation (11),

$E_{b}(s)=k_{m} \cdot w_{m}(s)$

Equation (13) through (16) can be represented with block diagram as shown in Figure 3.2.

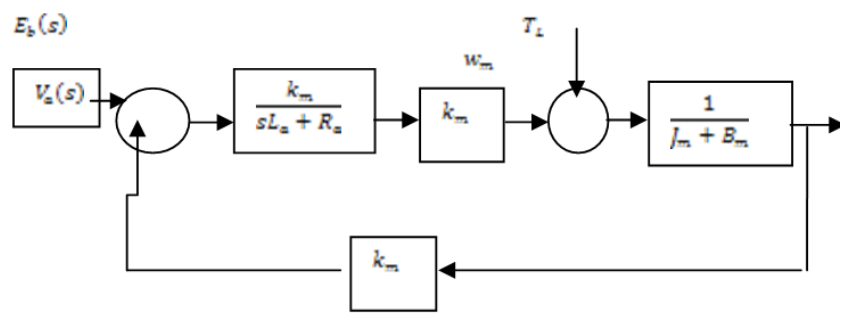

Fig. 2: Transfer function of a separately excited DC motor

The above block diagram can be reduced further to the form below by letting $T_{L}=0$, the equivalent transfer function can be obtained as shown below;

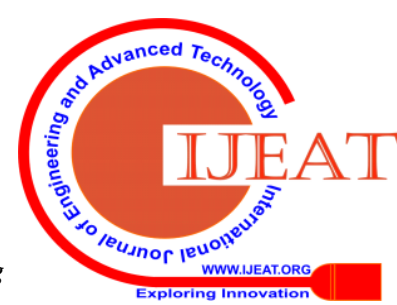




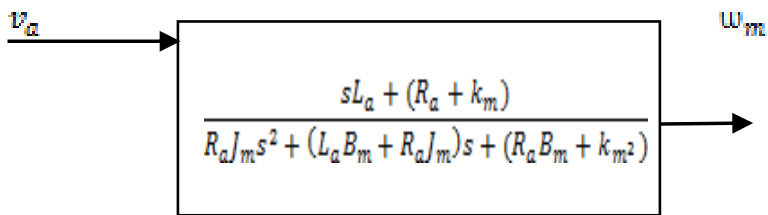

Fig. 3: Simplified diagram of transfer function of a separately excited DC motor

Considering the motor as a first-order module i.e. $L_{a}=0$.

$$
\begin{aligned}
& \frac{R_{a}+k_{m}}{R_{a} J_{m} s+\left(R_{a} B_{m}+k_{m^{2}}\right)} \\
& \text { Divide through by } R_{a} B_{m}+k_{m^{2}} ; \\
& \frac{\left(R_{a}+k_{m}\right) /\left(R_{a} B_{m}+k_{m}^{2}\right)}{\left(R_{a} / m s\right)}+1 \\
& \quad \frac{\left(R_{a} B_{m}+k_{m^{2}}\right)}{2} \quad k_{g}=\left(R_{a}+k_{m}\right) /\left(R_{a} B_{m}+k_{m^{2}}\right) \\
& \text { Let } T_{m}=\left(R_{a} J_{m}\right) /\left(R_{a} B_{m}+k_{m}^{2}\right)
\end{aligned}
$$

Thus, we have the transfer function as;

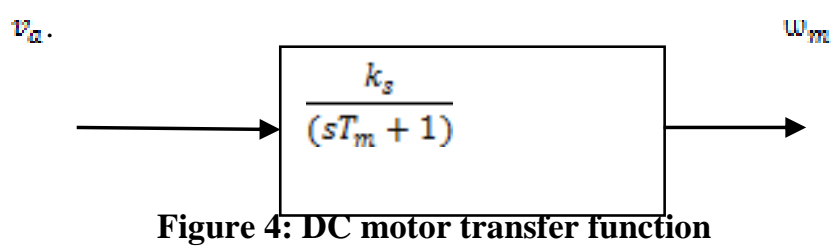

PI (Proportional Integral controller) is added to the above system to control the speed of the motor.

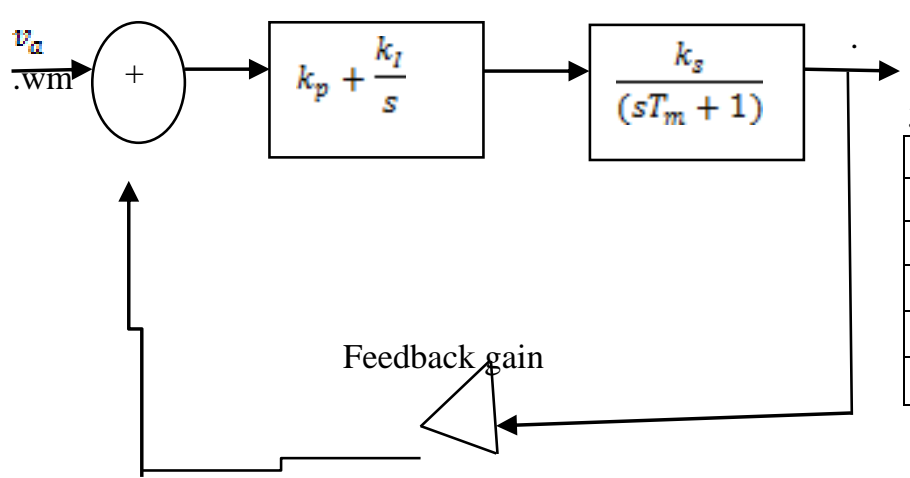

Fig. 5: Proportional Integral controller

Hence, we have.

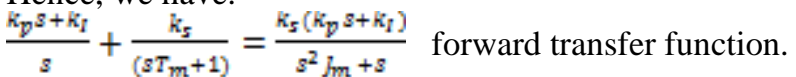

The transfer function with feedback gives,

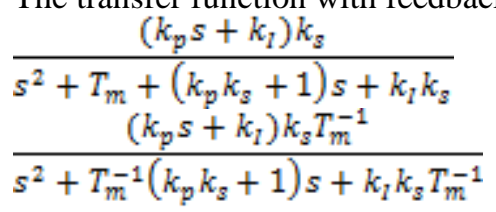

This should be compared with the standard second-order equations i.e

$$
\begin{aligned}
& s^{2}+2 \xi \omega_{m} s+\omega_{m}^{2}=0 \text { i.e } \\
& 2 \xi \omega_{m}=\frac{k_{p} k_{g}+1}{T_{m}} \\
& \omega_{m}^{2}=\frac{k_{g} k_{l}}{T_{m}}
\end{aligned}
$$

By choosing a damping coefficient $\xi=0.57$, and settling time to be $1.5 \mathrm{sec}$, we can calculate for the value of $k_{\mathrm{p}}$ and $k_{I}$. Also, for under damped system $\xi<1 t_{s}=\frac{4}{k w_{m}}$

3.4 CALCULATIONS

$t_{s}=\frac{4}{k w_{m}}$ and $t_{g}=1.5 \mathrm{sec}$.

$\mathrm{w}_{\mathrm{m}}=\frac{4}{1.5 * 0.57}=1.52 \mathrm{rad} / \mathrm{sec}$.

$k_{s}=\frac{R_{a}+k_{m}}{R_{a} B_{m}+k_{m}^{2}}=\frac{2+0.699}{2 * 10^{-9}+0.699^{2}}=4.333$

From equation (17),

$2 \xi \mathrm{w}_{\mathrm{m}}=\frac{k_{\mathrm{p}} k_{\mathrm{g}}+1}{T_{\mathrm{m}}}$

$2 * 0.57 * 1.52=\frac{k_{\mathrm{p}} * 5.524+1}{4.333}$

$k_{p}=1.19$

From equation (18),

$\omega_{n}^{2}=\frac{K_{s} K_{I}}{T_{m}}=\frac{5.524 * K_{I}}{4.33}=1.52^{2}$

$K_{I}=1.812$

Hence, we have $K_{p}=1.19$, and $K_{I}=1.812$

The PI controller can be designed as shown in Figure 6.

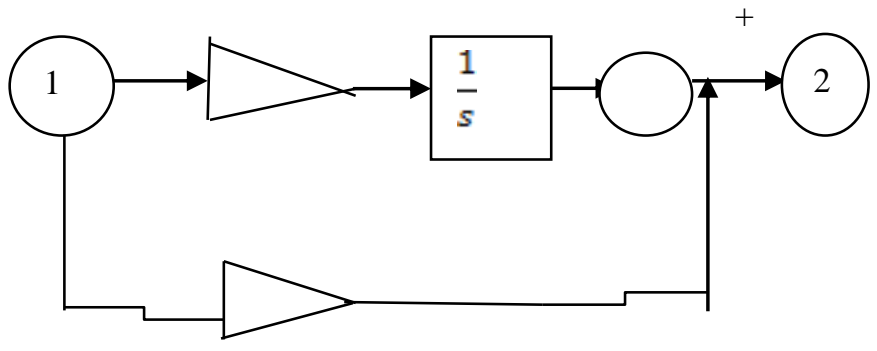

Fig. 6: Subsystem of a PI Controller

3.5 Parameters for the DC motor simulation

\begin{tabular}{|l|l|l|l|}
\hline Parameter & Value & Parameter & Value \\
\hline$R_{a}$ & 2 ohms & $B_{m}$ & $0.001 \mathrm{Nm}^{a}$ \\
\hline$L_{a}$ & $16.2 \mathrm{microHenry}$ & $T_{L}$ & $50 \mathrm{~N} . \mathrm{m}$ \\
\hline$R_{f}$ & 180 ohms & $K_{b}$ & 0.699 \\
\hline$L_{f}$ & 71.47 Henry & $V_{a}$ & $220 \mathrm{~V}$ \\
\hline$I_{m}$ & $0.117 k_{g} \times m^{2}$ & $V_{f}$ & $300 \mathrm{~V}$ \\
\hline
\end{tabular}

3.6 SIMULATIONS OF SPEED CONTROL OF SEPARATELY EXCITED DC MOTOR USING COMBINE ARMATURE AND FIELD CONTROL

The Simulink model which is for the open-loop characteristics of the motor is displayed in Figure 7. 


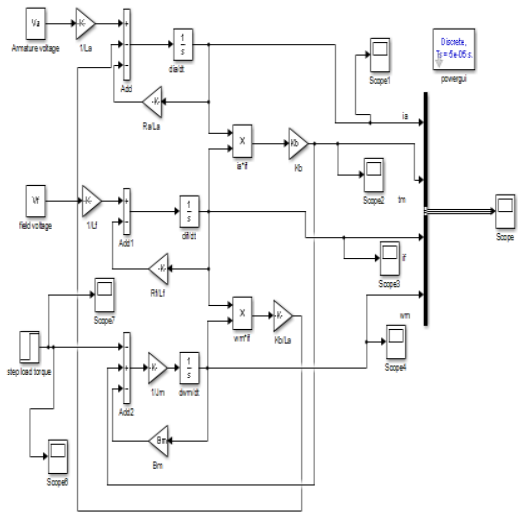

Fig. 7: Simulink model for separately excited DC motor.

The Simulink model shown in Figure 8 is for the closed-loop characteristics of the motor using a PI controller.

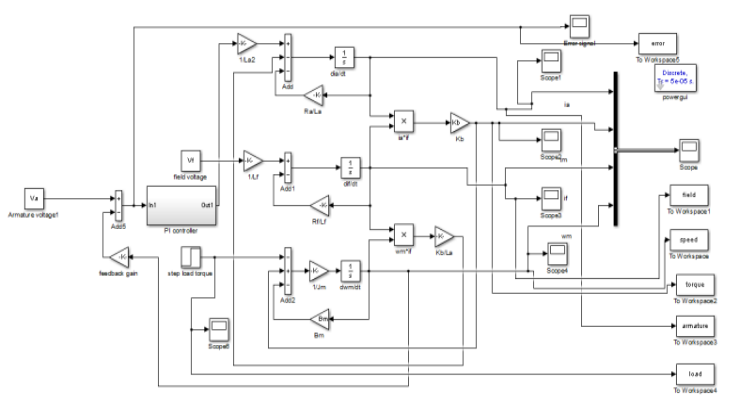

Fig. 8: Model for close-loop of a separately excited DC using a PI controller.

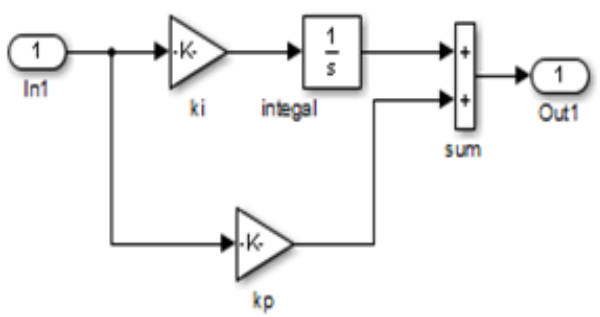

Fig. 9: Simulink model of PI controller.

\section{RESULTS AND DISCUSSIONS}

\subsection{SIMULATION RESULTS OF THE OPEN LOOP SYSTEM}

The graphs below give the no-load behavior of the separately excited dc motor.

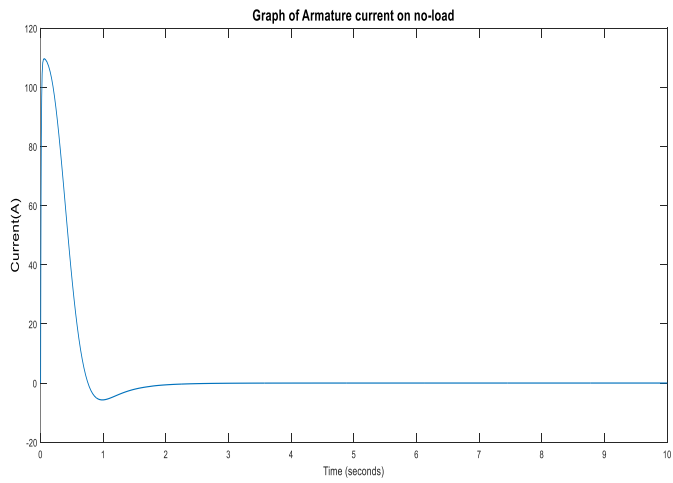

Fig. 10: Graph of armature current (A) on no-load

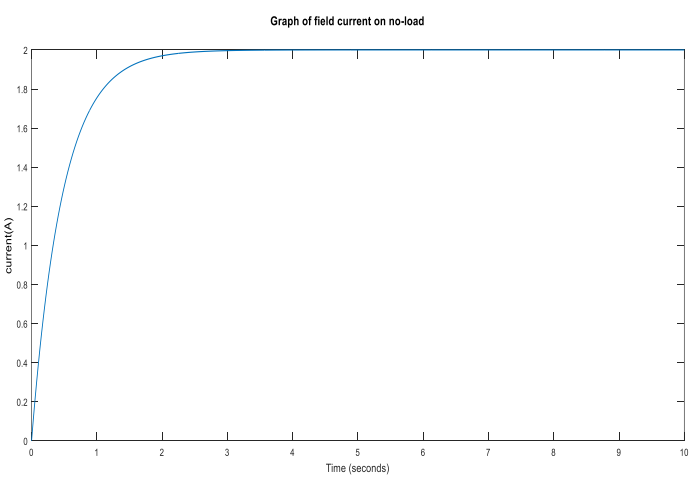

Fig. 11: Graph of field current (A) on no-load

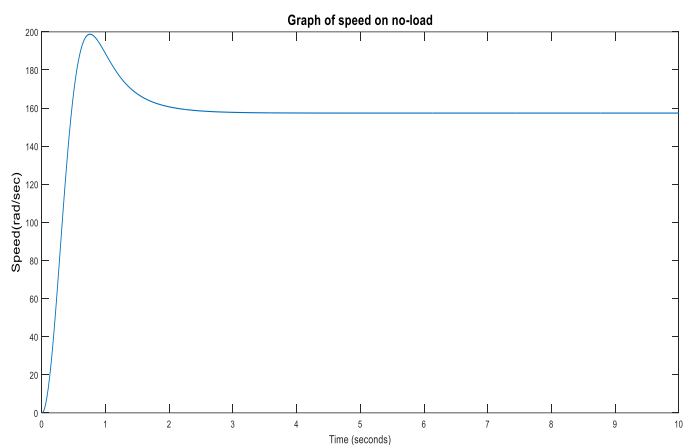

Fig. 12: Graph of motor speed (rad/sec) on no-load

The graphs below give the behavior of the separately excited dc motor when loaded with a load torque of $50 \mathrm{~N} / \mathrm{m}$.

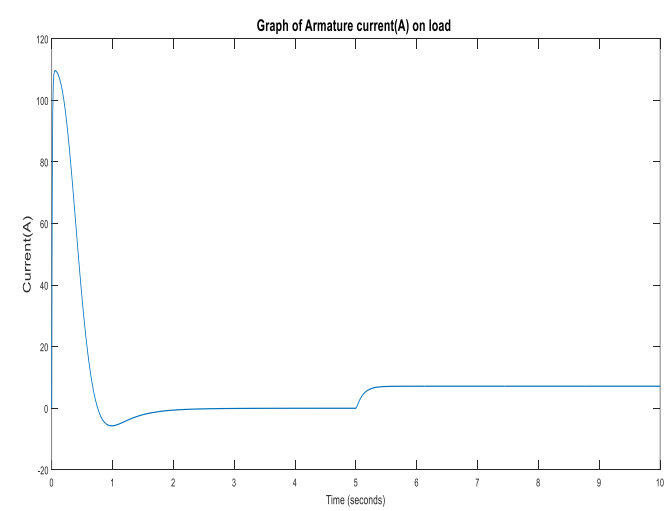

Fig. 13: Armature current (A) when loaded with a load torque of $50 \mathrm{~N} / \mathrm{m}$

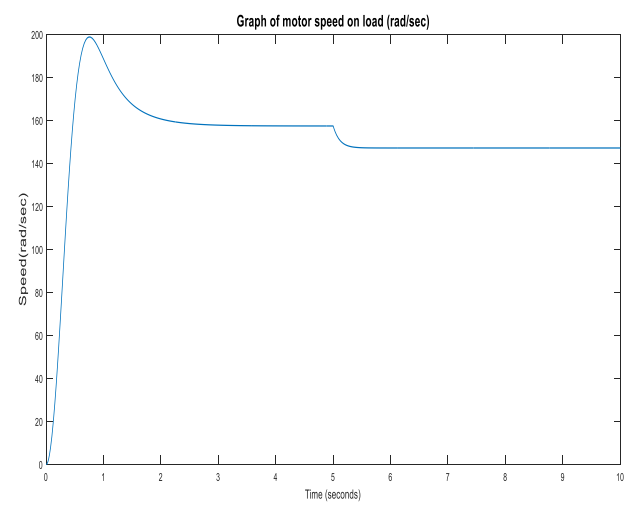

Fig. 14: Motor speed(rad/sec) when loaded with a load torque of $50 \mathrm{~N} / \mathrm{m}$

Published By:

Blue Eyes Intelligence Engineering 


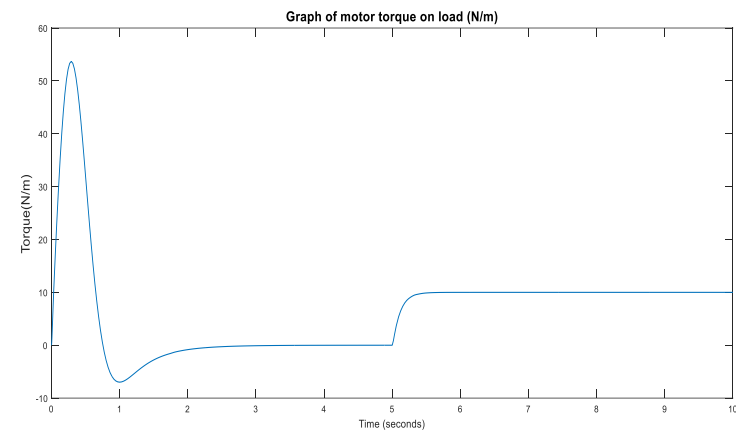

Fig. 15: Motor torque (N/m) when loaded with a load of $50 \mathrm{~N} / \mathrm{m}$.

\subsection{SIMULATION RESULTS OF THE CLOSED LOOP} SYSTEM

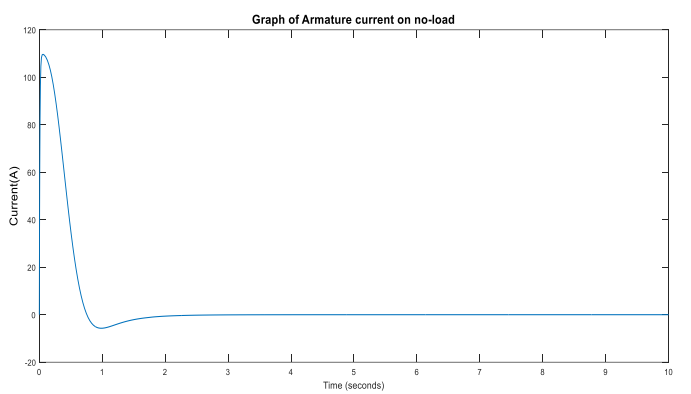

Fig. 16: Graph of armature current (A) on no-load

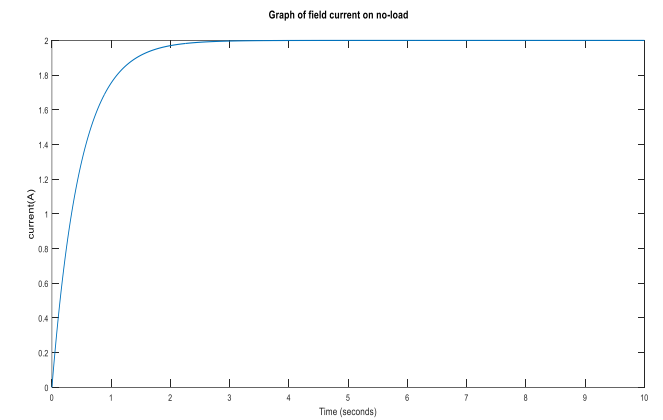

Fig.17: Graph of field current (A) on no-load

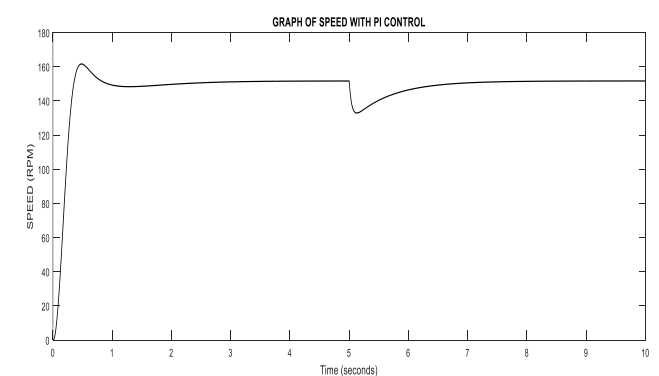

Fig. 18: Graph of the speed (Rpm) of the motor with a PI control.

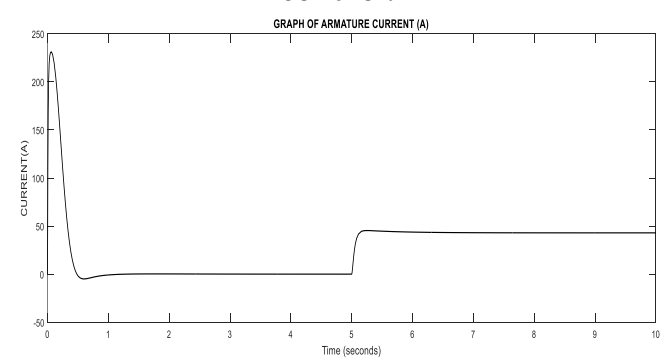

Fig. 19: Graph of the armature current (A) of the motor on closed loop control.

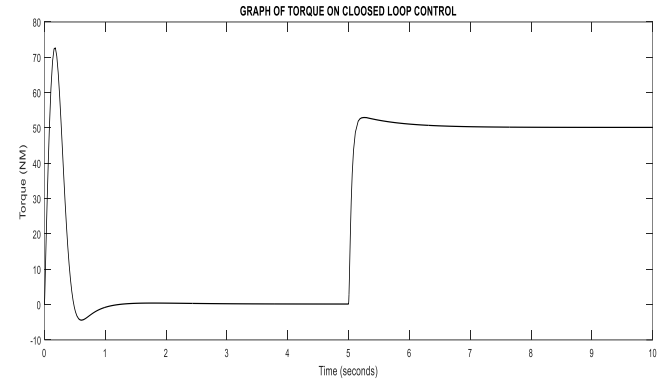

Fig. 20: Graph of the motor torque on closed loop control.

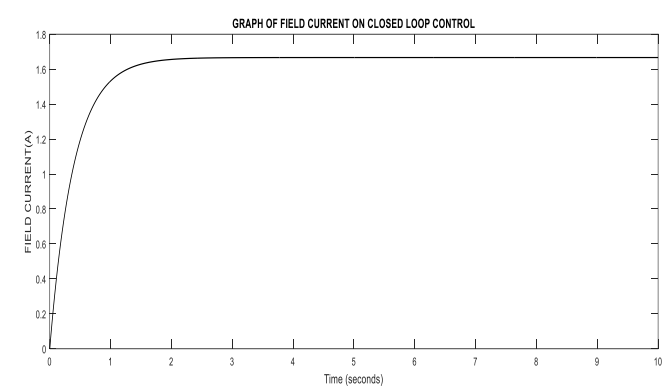

Fig. 21: Graph of the motor field current on closed loop control.

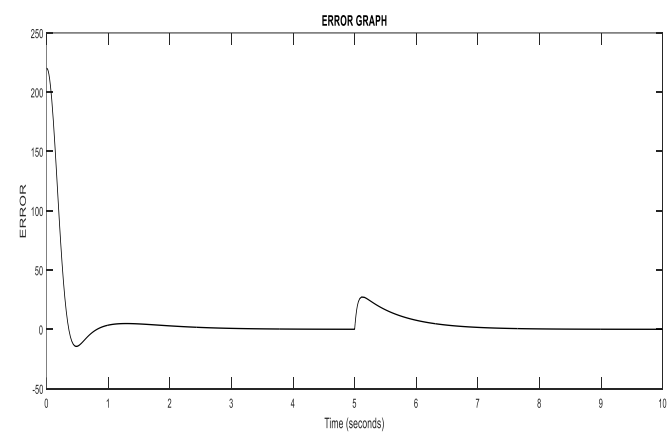

Fig. 22: Graph of the motor on closed loop control.

\subsection{DISCUSSION OF RESULTS}

From the graphs above, it can be deduced that when the motor is on sudden change of load, the speed decreased for a little while and started increasing from 6secs till it became constant at 8secs when the error is zero. During this duration, the torque of the motor increases steadily and was constant at 8secs as well when the error is zero, the armature current also increases as well due to increase in torque since the armature current has a linear relationship with torque and the speed is inversely proportional to the torque of the motor. The field current is always constant since we have kept it fixed; we only have control over the armature current. Comparing the results obtained both from open and close loop control system, it is observed that with the open loop, the speed was decreasing with time as more load is added but with the closed loop system, the speed decreased the moment load was added and rise to stability within a short second as a result of the PI controller.

\section{CONCLUSION}

It can be established that the major aim of this project which is the Control of DC motor Speed has been achieved.

Published By:

Blue Eyes Intelligence Engineering

Retrieval Number: C6043029320 /2020@BEIESP 
Considering the closed loop analysis using PI controller, it can be seen that the speed of the motor can be controlled and cannot be affected by change in load. Proportional Integral Controller has helped in controlling and maintaining the constant speeds at a reduced percentage overshoot and rise time. Since the issue of system and process control cannot be overemphasized, it therefore means that works directed towards such areas should be given a due attention both for immediate use and further improvement.

\section{REFERENCES}

1. Mustafa A. "Speed Control of DC motor using combine armature and field control", Doctoral programme (2) FEEC BUT, accessed online 11.02.2020.

2. Senthilkumar N., Sadasivam V., Prema K., "Design and simulation of fuzzy controller for closed loop of chopper fed embedded DC drives," IEEE International conference Powercon, Singapore, 2004.

3. Amit Kumar S, A.K Pandey; Intelligent PI controller for speed control of SEDM using MATLAB; International Journal of Engineering Science and Innovative Technology(IJESIT),volume 2,Issue 1,pp.180-189, January 2013.

4. Gaurav Kumar Mishra; A.K Pandey; Avinash Maurga; Combine armature and field speed control of dc motor for efficiency enhancement; SSRG -International Journal of Electrical and Electronics Engineering (SSRG-IJEEE)-volume1,Issue 6-pp.34 -39, August 2014.

5. Isaac, A., Victor, S., Mathematical Modeling and Computer Simulation of a Separately Excited dc Motor with Independent Armature/field control. In Proc., IEEE. Industrial Electronics, vol. 37, pp.483- 489, 2001. College of Electronics Engineering University of Mosul, Al-Rafidain, Vol.20, No 6, pp.117-129, December 2012.

6. Soundara R. Rajan , A comprehensive study on speed control of DC motor with field and armature control; International Journal of Engineering and Techniques-vol 3, Issue 6, pp. 806-810, Nov-Dec 2017.

7. Pranoti K. Speed control of separately excited DC motor using various Conventional Controllers; International Journal of Engineering Research and Applications.vol. 5, Issue 4, pp.67-72, April, 2015.

8. Vijay S., Vijay K. G., A comparative study on speed control of DC motor using intelligence techniques. International Journal of Electronic and Electrical Engineering, Vol. 7, No 4, pp.431-436, 2014.

9. Anurag D., "Speed control of DC shunt motor with field and armature rheostat control simultaneously" Advance in Electronic and Electrical Engineering, Research, Indian Publications. Vol.3, No1, pp.77-80, 2013.

10. Trupti G., Dani; B.S "PWM control chopper fed closed loop drive for DC motor using microcontroller" International Journal of Engineering Sciences and Research Technology; vol.4, pp.542 -546, April, 2015.

11. A. Sadiq, H. B. Mamman and M. Ahmed; Field Current Speed Control of Direct Current Motor using Fuzzy Logic Technique. International Journal of Information and Computation Technology. Vol.3, Number 8, pp.751- 756, 2013.

12. Aditya Pratap Singh et al; Speed Control of DC Motor using PID Controller Based on MATLAB; International Conference on Recent Trends in Applied Sciences with Engineering Applications, Vol.4, No 6, pp.22- 28, 2013.

13. D. Vimalakeerthy; Time Response Analysis of DC Motor using Armature Control Method and Performance Improvement using PID Controller. European Journal of Advances in Engineering and Technology, Vol.2, No 6, pp.56 -61, 2015.

14. Satish A. and Samikshya T., Comparison of Speed Control of DC Motor using PID Controller and Various Optimization Techniques a Review; International Journal of Engineering Science and Computing, Vol.7, Issue No.7, pp.4884 -4892, 2017.

15. S. R. Bhagwatkar, A.P. Dhande, A Review on Automatic Closed Loop Speed Control of a DC Motor. International Journal of Advanced Research in Computer and Communication Engineering, Vol.4, Issue 1, pp137-139, January 2015.

16. Hardik S Jain, Akshat Palak, Sandesh Agrawal, Krishnam Tibrewal and Malaya K. Hota, DC Motor Speed Control using PID Controller, IR Sensor and PWM Hysteresis, International Journal of Innovative Technology and Exploring Engineering (IJITEE), Volume-8 Issue-6, pp.781- 786 , April 2019

\section{AUTHORS PROFILE}

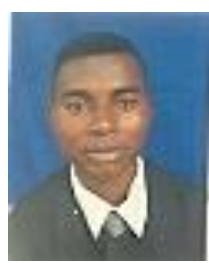

Engr. Dr. Stephen Ejiofor Oti, received a B.Eng. (Electrical Engineering), an M.Eng. (Electrical Power Devices) and a Ph.D (Electrical Power Devices) degrees, all of the University of Nigeria in 1998, 2006 and 2014 respectively. He joined the Electrical Engineering Department, UNN as a Principal Technical Officer and was later in 2007 converted to the lecturing cadre in the same department. He is a member of Nigerian Society of Engineers (NSE). He is the current membership secretary of Nsukka Chapter of Nigerian Institute of Electrical and Electronic Engineering (NIEEE) and he is also a registered member of Council for the Regulation of Engineering in Nigeria (COREN). He has several research articles published both in local and international journals. His research areas include Machine modeling, Thermal modeling, Power and Energy systems modeling and Simulations.

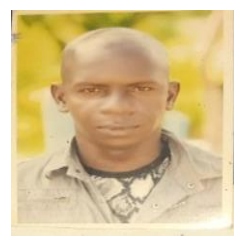

Engr. Stephen Chinwendu Agada, hails from Aku in Igbo-etiti Local Government Area of Enugu state of Nigeria. He received a B.Eng. (Electrical Engineering) in1998 from the University of Nigeria, an M.Eng. (Power System) from the Enugu State University of Science and Technology. He is currently pursuing his Ph.D (Electrical Power \& Machines) at Michael Okpara University of Agriculture, Umudike. Agada has published some articles in local and international journals and he is fully registered with the Council for the Regulation of Engineering in Nigeria (COREN). His research areas include Machine modeling and Power systems Analysis and Simulations.

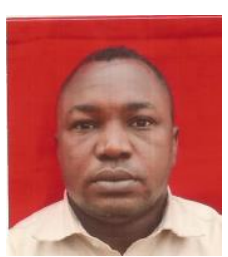

Mr. Chinedu T. Obe, received a B.Eng. (Electrica Engineering) of University of Nigeria, Nsukka in 2014 and proceeded for the National Youth Service Corp. He thereafter enrolled for, and bagged the M.Eng. (Electrical Power Devices) degree, also of the University of Nigeria in 2018. His mind and eyes are presently focused on Ph.D. work. C.T. Obe joined the Electrical Engineering Department, UNN as a Technologist and was later in 2019 converted to the lecturing cadre in the same department. He has started publishing in in some reputable Journals.

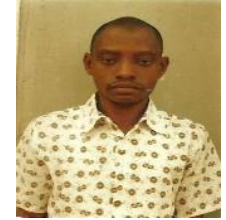

Mr. Ahmed Rufai Salihu, graduated from Federa University of Technology, Niger State, in 2008 and obtained a Master of Engineering (M.Eng.) degree programme from the Department of Electrical and Electronic Engineering, University of Benin, Benin-City, Edo State, Nigeria in 2017. He is currently a staff of Electrical Engineering Department, University of Nigeria, Nsukka. He is a corporate member of the Nigeria Society of Engineers (NSE). His research interests include Electric Power System Analysis, Machine Modeling and Simulation.

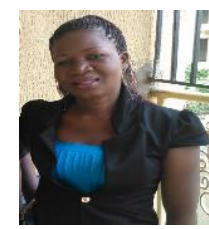

Dr. Uche. C. Ogbuefi, specializes in Electrical Power Systems. She obtained her Doctorate Degree in Electrical Engineering from University of Nigeria, Nsukka. She worked with many companies before she joined the academic world as a Lecturer in the Department of Electrical Engineering, University of Nigeria, Nsukka. She is a corporate member of the Nigeria Society of Engineer (NSE), a COREN registered Engineer and also a member of Association of Professional Women in Engineering (PWEN). She is also a member of the International Association of Engineers (IAENG). She has articles published in both local and international journals and conference proceedings. She has also authored and co-authored some book chapters. Her research interest include Electric Power Systems; Optimization, Fault Analysis, Renewable Energy Resources, Renewable Energy Technology, and Integration. 